\title{
Thin basement membrane nephropathy: is there genetic predisposition to more severe disease?
}

\author{
Constantinos Deltas
}

Received: 17 September 2008 /Revised: 10 October 2008 / Accepted: 13 October 2008 / Published online: 19 November 2008

(C) The Author(s) 2008. This article is published with open access at Springerlink.com

Sirs,

For a patient who presents with isolated microscopic hematuria, three different disease entities that enter the differential diagnosis are: (a) immunoglobulin A (IgA) nephropathy, with no family history, that may also express itself with macroscopic hematuria; (b) Alport syndrome, which may present with episodes of macroscopic hematuria during childhood and should most frequently be explained by a family history of chronic kidney disease (most frequently X-linked, $85 \%$ and, less frequently, of autosomal recessive inheritance); (c) thin basement membrane nephropathy (TBMN), which invariably leads to benign familial microscopic hematuria (BFMH), with family history and infrequent episodes of macroscopic hematuria, while it is normally not expected to be accompanied by severe kidney disease, apart from low-grade proteinuria.

TBMN as a heritable condition has been attributed to heterozygous mutations in the collagen type IV, alpha 3 and alpha 4 (COL4A3/COL4A4) genes on chromosome 2q3637 , by nearly $50 \%$. It should not be a surprise if closer look and improved techniques prove that COL4A3/COL4A4 mutations account for an even higher portion of TBMN cases that presently have been overlooked. The term TBMN, with only few exceptions, has largely been used as a synonym for benign familial microscopic hematuria, which nearly always is the only symptom, with excellent prognosis [1-3]. Those few exceptions are worth concentrating on, in view of a recent publication from my

C. Deltas $(\bowtie)$

Department of Biological Sciences, University of Cyprus,

Kallipoleos 75,

1678 Nicosia, Cyprus

e-mail: Deltas@ucy.ac.cy laboratory, which provides voluminous exceptional data from a population on the island of Cyprus [4]. In that report we described 13 families with the dual diagnosis of TBMN and focal segmental glomerulosclerosis (FSGS), while, in ten of them, we identified three heterozygous mutations in the COL4A3/COL4A4 genes. Combination of that data with more recent work concludes that, in a total of 59 patients over the age of 51 years, approximately two in three had developed proteinuria and chronic kidney disease, while about one in three had progressed to end-stage kidney disease (ESKD), as evidenced by the need for hemodialysis or kidney transplantation [4, 5 and unpublished results].

Older publications had attested to similar exceptions as regards the prognosis of TBMN, reporting on relatively small numbers of patients, a few of whom had presented also with additional glomerular pathologies that included proteinuria, FSGS and chronic kidney disease, occasionally also ESKD. As early as 1985, Dische et al. [6] reported on 14 TBMN patients aged 11-51 years, several of whom had progressive disease including hypertension and renal impairment, while one had reached ESKD. Nieuwhof et al. [7], in a prospective 12-year follow-up study of 19 patients with TBMN and microscopic (18/19) or macroscopic hematuria $(1 / 19)$, were the first to clearly associate TBMN with late-onset renal impairment in elderly patients. In $13.5 \%$ of their patients focal global glomerulosclerosis was detected, while six first-degree relatives reached ESKD, prompting the authors to conclude that TBMN predisposes to premature glomerular obsolescence, which, with sufficient time, leads to increased incidence of hypertension and late-onset renal insufficiency. Interestingly, the same authors mentioned that in a separate series of TBMN patients they had noted an increased proteinuria associated with FSGS in the renal biopsy. Based on their admittedly small patient cohort the authors commented that the prognosis of TBMN may not be as benign as generally 
thought. Subsequent reports described similar findings where, occasionally, TBMN patients did not follow a benign course but, rather, they progressed to FSGS and proteinuria or hypertension that developed into chronic kidney disease or ESKD, thereby prompting the authors to allude to other co-inherited glomerulopathies or to the notion that TBMN predisposes to renal impairment $[8,9]$. Obviously, oftentimes, TBMN can be a benign disease; however, in the presence of additional symptoms such as proteinuria or a family history of kidney failure, a renal biopsy is clearly warranted in addition to close follow up $[10,11]$.

In view of the above findings and the findings by Voskarides et al. [4], it was tempting to hypothesize that TBMN is not always a benign condition but rather a situation which predisposes COL4A3/COL4A4 heterozygous carriers to a higher risk for proteinuria or FSGS and renal failure, when another genetic modifier is co-inherited. In a recent publication in this journal Tonna et al. [12] reported on $56 \mathrm{TBMN}$ patients (on the basis of persistent hematuria), some of whom also had proteinuria of $\geq 300 \mathrm{mg} / \mathrm{l}$, or $\geq 500 \mathrm{mg} / \mathrm{l}$. Among these, 3 of $5(60 \%)$ who carried the R229Q variant of the glomerular filtration barrier protein podocin [encoded by the nephrosis 2 (NPHS2) gene] had proteinuria of $\geq 500 \mathrm{mg} / \mathrm{l}$, whereas only 7 of $51(14 \%)$ who did not carry R229Q had a similar level of proteinuria. This showed statistical significance, although the numbers are somewhat small, clearly needing confirmation by independent larger studies. This implies that TBMN patients who are also heterozygous carriers of the R229Q variant in podocin are predisposed to a somewhat more severe phenotype. However, in the same cohort, none of nine patients with TBMN and coincidental glomerular or tubulointerstitial disease carried R229Q, thereby not supporting the notion of a confounding negative role. Also, from work in my laboratory, none of 43 patients over 45 years of age with TBMN and a proven COL4A3/COL4A4 mutation and documented proteinuria or chronic kidney disease carried this podocin variant (unpublished results). This variant has a frequency of $4 \%$ in the general Cypriot population. It is worth mentioning that, although an earlier report had associated R229Q with microalbuminuria in the Brazilian population, a more recent work with larger numbers did not corroborate those data in a US adult population [13, 14].

In conclusion, the implication that variant R229Q in the podocin protein may predispose to proteinuria in TBMN [12] is somewhat premature and needs further experimentation. It is equally important either to confirm this association or to reject it; however, it is of paramount importance for us to identify the factor or factors that clearly predispose a subgroup of TBMN patients to proteinuria, or even FSGS and renal failure, thereby enabling us to identify high-risk patients for early interven- tion. Apparently, founder phenomena and geographic clustering may have contributed to the unusual findings in the Cypriot population where a high proportion of COL4A3/COL4A4 carriers proceed to FSGS and renal failure $[4,5]$.

Acknowledgments This work was funded mainly through a grant by the Cyprus Research Promotion Foundation, ENI $\Sigma X / 0505 / 02$, and partly by the Cyprus Ministry of Health, the Cyprus Kidney Association and the University of Cyprus (Research Activities 3/311). The author declares that he has no competing financial interests.

Open Access This article is distributed under the terms of the Creative Commons Attribution Noncommercial License which permits any noncommercial use, distribution, and reproduction in any medium, provided the original author(s) and source are credited.

\section{References}

1. Lemmink HH, Nillesen WN, Mochizuki T, Schroder $\mathrm{CH}$, Brunner HG, van Oost BA, Monnens LA, Smeets HJ (1996) Benign familial hematuria due to mutation of the type IV collagen alpha4 gene. J Clin Invest 98:1114-1118

2. Savige J, Rana K, Tonna S, Buzza M, Dagher H, Wang YY (2003) Thin basement membrane nephropathy. Kidney Int 64:1169-1178

3. Kashtan CE (2005) Familial hematurias: what we know and what we don't. Pediatr Nephrol 20:1027-1035

4. Voskarides K, Damianou L, Neocleous V, Zouvani I, Christodoulidou S, Hadjiconstantinou V, Ioannou K, Athanasiou Y, Patsias C, Alexopoulos E, Pierides A, Kyriakou K, Deltas C (2007) COL4A3/ COL4A4 mutations producing focal segmental glomerulosclerosis and renal failure in thin basement membrane nephropathy. J Am Soc Nephrol 18:3004-3016

5. Voskarides K, Patsias C, Pierides A, Deltas C (2008) COL4A3 founder mutations in Greek-Cypriot families with thin basement membrane nephropathy and focal segmental glomerulosclerosis dating from around 18th century. Genet Test 12:273-278

6. Dische FE, Weston MJ, Parsons V (1985) Abnormally thin glomerular basement membranes associated with hematuria, proteinuria or renal failure in adults. Am J Nephrol 5:103-109

7. Nieuwhof CMG, de Heer F, de Leeuw P, van Breda Vriesman PJC (1997) Thin GBM nephropathy: premature glomerular obsolescence is associated with hypertension and late onset renal failure. Kidney Int 51:1596-1601

8. Nogueira M, Cartwright J Jr, Horn K, Doe N, Shappell S, Barrios $\mathrm{R}$, Coroneos E, Truong LD (2000) Thin basement membrane disease with heavy proteinuria or nephrotic syndrome at presentation. Am J Kidney Dis 35:E15

9. van Paasen P, van Breda Vriesman PJ, van Rie H, Tervaert JW (2004) Signs and symptoms of thin basement membrane nephropathy: a prospective regional study on primary glomerular diseaseThe Limburg Renal Registry. Kidney Int 66:909-913

10. Norby SM, Cosio FG (2005) Thin basement membrane nephropathy associated with other glomerular diseases. Semin Nephrol 25:176-179

11. Kashtan CE (2007) The wages of thin. J Am Soc Nephrol 18:2800-2802

12. Tonna S, Wang YY, Wilson D, Rigby L, Tabone T, Cotton R, Savige J (2008) The R229Q mutation in NPHS2 may predispose 
to proteinuria in thin-basement-membrane nephropathy. Pediatr Nephrol 23:2201-2207

13. Pereira AC, Pereira AB, Mota GF, Cunha RS, Herkenhoff FL, Pollak MR, Mill JG, Krieger JE (2004) NPHS2 R229Q functional variant is associated with microalbuminuria in the general population. Kidney Int 65:1026-1030
14. Köttgen A, Hsu CC, Coresh J, Shuldiner AR, Berthier-Schaad Y, Gambhir TR, Smith MW, Boerwinkle E, Kao WH (2008) The association of podocin R229Q polymorphism with increased albuminuria or reduced estimated GFR in a large population-based sample of US adults. Am J Kidney Dis $52: 868-875$ 